TẠP CHÍ KHOA HỌC ĐẠI HỌC TÂN TRÀO
ISSN: $2354-1431$

\title{
PHÂN TÍCH CÁC YẾU TỐ ẢNH HƯởNG ĐẾN KẾT QUẢ VÀ HIỆU QUẢ KINH TẾ CỦA Hộ TRỒNG CAM Ở TỈNH TUYÊN QUANG
}

Trần Thị Diên ${ }^{a^{*}}$

${ }^{a}$ Truoòng Đại học Tân Trào

*Email: tranthidien1979@gmail.com

\section{Thông tin bài viết}

Ngày nhận bài:

2/4/2020

Ngày duyệt đăng:

$10 / 6 / 2020$

Tù khóa:

Quả cam, hiệu quả kinh tế, hộ trồng cam, Tuyên Quang, yếu tố ảnh hiởng, doanh thu và thu nhập của hộ.

\section{Tóm tắt}

Nghiên cứu đã khảo sát 150 hộ trồng cam ở tỉnh Tuyên Quang và sử dụng một số phương pháp nghiên cứu kinh tế để phân tích các yếu tố ảnh hưởng đến doanh thu và thu nhập từ sản xuất cam của nông hộ. Kết quả phân tích từ mô hình hồi quy đa biến cho thấy các yếu tố như kinh nghiệm, tập huấn, quy hoạch, vay vốn, mô hình sản xuất cam VietGAP, mức độ đầu tư đều có ảnh hưởng tích cực đến doanh thu bán cam của hộ sản xuất. Phân tích các yếu tố ảnh hưởng đến hiệu quả kinh tế sản xuất cam của hộ là căn cứ để đề xuất các giải pháp nhằm nâng cao thu nhập của hộ trồng cam như: Nâng cao năng lực sản xuất cho nông hộ; Mở rộng quy mô diện tích đất trồng cam/hộ; Tăng cường nguồn vốn đầu tư; Nhân rộng mô hình sản xuất cam VietGAP; Tổ chức quy hoạch tốt vùng sản xuất cam tập trung; Sử dụng các giống cam rải vụ và các biện pháp bảo quản, chế biến để kéo dài thời gian tiêu thụ sản phẩm; Tăng cường liên kết trong sản xuất và tiêu thụ cam.

\section{1. ĐẠTT VẤN ĐỀ}

Cây cam (tên khoa học là Citrus sinensis Osbeck) là cây ăn quả lâu năm, sinh trưởng tốt trong điều kiện sinh thái của tỉnh Tuyên Quang, hiện nay cây cam đang được xác định là một trong những loại cây trồng thế mạnh của tỉnh Tuyên Quang, có giá trị kinh tế cao, mang lại nguồn thu nhập cao cho người dân, giúp xóa đói giảm nghèo, giải quyết việc làm cho lao động nông thôn. Năm 2005, cây cam được trồng chủ yếu ở huyện Hàm Yên với diện tích 2.572 ha, đến năm 2019, diện tích trồng cam của toàn Tỉnh đạt 8.800 ha, diện tích cam cho thu hoạch là 5.777 ha, với gần 6000 hộ trồng cam [2]. Tình hình biến động về diện tích, năng suất, sản lượng và giá trị sản xuất cam ở tỉnh Tuyên Quang giai đoạn 2017 - 2019 được tổng hợp qua bảng 1 .

\section{Bảng 1. Diện tích, năng suất, sản lượng và giá trị sản xuất cam}

ở tỉnh Tuyên Quang giai đoạn 2017 - 2019

\begin{tabular}{|c|l|c|c|c|c|c|c|c|}
\hline \multirow{2}{*}{ TT } & \multicolumn{1}{|c|}{ Chỉ tiêu } & ĐVT & $\begin{array}{c}\text { Năm } \\
\mathbf{2 0 1 7}\end{array}$ & $\begin{array}{c}\text { Năm } \\
\mathbf{2 0 1 8}\end{array}$ & $\begin{array}{c}\text { Năm } \\
\mathbf{2 0 1 9}\end{array}$ & $\begin{array}{c}\mathbf{2 0 1 8} / \\
\mathbf{2 0 1 7}\end{array}$ & $\begin{array}{c}\mathbf{2 0 1 9 /} \\
\mathbf{2 0 1 8}\end{array}$ & BQ \\
\hline 1 & Diện tích trồng cam & ha & 8.330 & 8.630 & 8.800 & 103,6 & 102,0 & 102,8 \\
\hline 2 & Diện tích cam thu hoạch & ha & 4.920 & 5.530 & 5.770 & 112,4 & 104,4 & 108,4 \\
\hline
\end{tabular}




\begin{tabular}{|c|l|c|c|c|c|c|c|c|}
\hline TT & \multicolumn{1}{|c|}{ Chỉ tiêu } & ĐVT & $\begin{array}{c}\text { Năm } \\
\mathbf{2 0 1 7}\end{array}$ & $\begin{array}{c}\text { Năm } \\
\mathbf{2 0 1 8}\end{array}$ & $\begin{array}{c}\text { Năm } \\
\mathbf{2 0 1 9}\end{array}$ & $\begin{array}{c}\mathbf{2 0 1 8} \\
\mathbf{2 0 1 7}\end{array}$ & $\begin{array}{c}\mathbf{2 0 1 9 /} \\
\mathbf{2 0 1 8}\end{array}$ & $\mathbf{B Q}$ \\
\hline 3 & Năng suất & tấn/ha & 13,8 & 15,2 & 16,6 & 110,1 & 109,2 & 109,7 \\
\hline 4 & Sản lượng & nghìn tấn & 68 & 84 & 95 & 123,5 & 113,1 & 118,3 \\
\hline 5 & Giá bán bình quân & ng.đ/kg & 9,3 & 8,2 & 7,7 & 88,2 & 93,9 & 91,0 \\
\hline 6 & Giá trị sản xuất cam & tỷ đồng & 632 & 688 & 731 & 108,9 & 106,3 & 107,6 \\
\hline
\end{tabular}

(Nguồn: Niên giám thống kê tỉnh Tuyên Quang [1]; số liệu điều tra 2019)

Số liệu bảng 1 cho thấy, diện tích, năng suất và sản lượng cam của tỉnh Tuyên Quang không ngừng gia tăng qua các năm, tuy nhiên khi sản lượng gia tăng thì giá bán sản phẩm lại giảm, người trồng cam lại gặp khó khăn trong tiêu thụ sản phẩm. Theo Đề án phát triển vùng sản xuất cam tập trung, đến năm 2025 diện tích cam toàn Tỉnh dự kiến sẽ mở rộng lên 10.000 ha, tăng diện tích trồng cam theo hướng VietGAP [6]. Tuy nhiên, việc mở rộng hơn nữa diện tích cam cần gắn với quy hoạch về bảo quản, chế biến và mở rộng thị trường tiêu thụ, nếu không sẽ dẫn đến tình trạng "được mùa, mất giá" như nhiều vùng sản xuất trái cây của Việt Nam.

Tỉnh Tuyên Quang đã triển khai thực hiện một số giải pháp phát triển sản xuất cam như: Chính sách và quy hoạch phát triển vùng sản xuất cam tập trung; Hỗ trợ sản xuất hàng hóa; Xây dựng Đề án phát triển vùng sản xuất cam tỉnh Tuyên Quang giai đoạn 2014-2020 [5]; Triển khai thực hiện một số dự án như: Cải tạo, nâng cấp cơ sở hạ tầng phát triển vùng trồng cam sành Hàm Yên; Phát triển chuỗi giá trị cam Hàm Yên; Xây dựng chợ đầu mối cam sành tại huyện Hàm Yên; Quy hoạch sử dụng đất trồng cam đến năm 2020, định hướng đến năm 2030. Các giải pháp trên đã mang lại những kết quả và hiệu quả kinh tế cao trong phát triển sản xuất cam ở tỉnh Tuyên Quang [4]. Tuy nhiên sản xuất cam của nông hộ chủ yếu mang tính tự phát và thủ công, chưa sản xuất theo hướng hàng hóa đáp ứng nhu cầu của thị trường. Sản phẩm thu hoạch chủ yếu bán trôi nổi trên thị trường trong nước, giá bán thấp. Việc tiêu thụ sản phẩm mang tính thời vụ cao, cam đã có thương hiệu nhưng tiêu thụ còn khó khăn, giá cả và thị trường tiêu thụ sản phẩm còn nhiều rủi ro, bất ổn. Nghiên cứu phân tích các yếu tố ảnh hưởng đến doanh thu và thu nhập từ sản xuất cam của hộ là cần thiết, nhằm đề xuất các giải pháp nâng cao hiệu quả kinh tế trong sản xuất cam của nông hộ ở tỉnh Tuyên Quang.

\section{NỘI DUNG VÀ PHƯƠNG PHÁP NGHIÊN CÚU}

Nghiên cứu sử dụng mô hình kinh tế hồi quy đa biến để lượng hóa các yếu tố ảnh hưởng đến doanh thu bán cam bình quân trên ha (DT/ha) của hộ điều tra. Mô hình hồi quy đa biến được xác định như sau: DT/ha $=\beta_{0}+\beta 1$ Kinhnghiem $+\beta 2$ Taphuan $+\beta 3$ Quyhoach $+\beta 4$ Vayvon $+\beta 5$ Mohinh $+\beta 6$ Lienket $+\beta 7$ CPSX/ha $+\beta 8$ Thuhoach $+\beta 9$ Tieuthu.

Các biến sử dụng trong mô hình được giải thích ở bảng 2 .

Bảng 2. Các biến sử dụng trong mô hình hồi quy tuyến tính đa biến

\begin{tabular}{|c|c|c|}
\hline Mã hóa biến & Định nghĩa biến & Đơn vị tính \\
\hline DT/ha & Biến phụ thuộc: Doanh thu bán cam hàng hóa/ha của hộ trồng cam & triệu đồng \\
\hline Kinhnghiem & Số năm kinh nghiệm trồng cam của chủ hộ & năm \\
\hline Taphuan & Số lần hộ tham gia tập huấn trong 1 năm & lần \\
\hline Quyhoach & $\begin{array}{l}\text { Quy hoạch: Giá trị là } 1 \text { nếu hộ nằm trong vùng quy hoạch; Giá trị là } \\
0 \text { nếu hộ nằm ngoài vùng quy hoạch }\end{array}$ & $1=$ có $0=$ không \\
\hline Vayvon & $\begin{array}{l}\text { Vay vốn: Giá trị là } 1 \text { nếu hộ có vay vốn; Giá trị là } 0 \text { nếu hộ không } \\
\text { vay vốn }\end{array}$ & $1=$ có 0 = không \\
\hline Mohinh & $\begin{array}{l}\text { Mô hình sản xuất: Giá trị là } 1 \text { nếu hộ áp dụng mô hình VietGAP; Giá } \\
\text { trị là } 0 \text { nếu hộ sản xuất theo mô hình truyền thống. }\end{array}$ & $1=$ có 0 = không \\
\hline
\end{tabular}




\begin{tabular}{|c|c|c|}
\hline Mã hóa biến & Định nghĩa biến & Đơn vị tính \\
\hline Lienket & $\begin{array}{l}\text { Liên kết: Giá trị là } 1 \text { nếu hộ có tham gia liên kết; Giá trị là } 0 \text { nếu hộ } \\
\text { không tham gia liên kêt. }\end{array}$ & $1=$ có 0 = không \\
\hline CPSX/ha & Chi phí sản xuất bình quân trên ha của hộ & triệu đồng \\
\hline Thuhoach & $\begin{array}{l}\text { Thời điểm thu hoạch cam: Giá trị là } 1 \text { nếu hộ thu hoạch trái vụ hoặc kết } \\
\text { hợp; Giá trị là } 0 \text { nếu hộ thu hoạch chính vụ. }\end{array}$ & $\begin{array}{l}1=\text { trái vụ, kết hợp; } 0= \\
\text { chính vụ }\end{array}$ \\
\hline Tieuthu & $\begin{array}{l}\text { Phương thức tiêu thụ: Giá trị là } 1 \text { nếu hộ bán lẻ hoặc kết hợp; Giá trị } \\
\text { là } 0 \text { nếu hộ bán buôn }\end{array}$ & $\begin{array}{l}\text { 1= bán lẻ, kết hợp; } 0= \\
\text { bán buôn }\end{array}$ \\
\hline
\end{tabular}

Trên cơ sở mô hình hồi quy đa biến và số liệu điều tra, nghiên cứu sử dụng phần mềm SPSS 22.0 để phân tích, xử lý số liệu và đưa ra các kết luận về mức độ ảnh hưởng của các yếu tố đến doanh thu bán cam của nông hộ.

Nghiên cứu sử dụng các phương pháp thống kê, phương pháp hạch toán kinh tế để phân tích các yếu tố ảnh hưởng đến hiệu quả kinh tế của hộ trồng cam. Chỉ tiêu chủ yếu được sử dụng để phân tích, đánh giá hiệu quả kinh tế trong nghiên cứu này là thu nhập hỗn hợp (MI). Nghiên cứu đã phân tích và đánh giá mức độ ảnh hưởng của các yếu tố như quy mô sản xuất, vay vốn, mô hình sản xuất cam VietGAP, tổ chức vùng sản xuất, thời điểm tiêu thụ cam, là những yếu tố có ảnh hưởng đến hiệu quả kinh tế trong sản xuất của hộ trồng cam.

Số liệu sơ cấp được thu thập bằng phương pháp khảo sát bằng bảng hỏi đối với các hộ trồng cam. Số hộ trồng cam trên địa bàn tỉnh Tuyên Quang hiện nay là 5.900 hộ. Áp dụng công thức Slovin để tính cỡ mẫu:

$$
n=\frac{N}{1+N(e)^{2}}
$$

Như vậy, với $\mathrm{N}=5.900$, độ tin cậy là $90 \%$ và $\mathrm{P}=0,1$, cỡ mẫu với sai số cho phép $e$ là $\pm 10 \%$, xác định được $\mathrm{n}=$ 98 hộ. Tuy nhiên, trong phân tích hồi quy đa biến, cỡ mẫu tối thiểu cần đạt tính theo công thức: $\mathrm{n}=50+(8 \mathrm{x} \mathrm{m})$, trong đó m là số biến độc lập (Tabachnick and Fidell, 1996). Nghiên cứu phân tích các yếu tố ảnh hưởng đến doanh thu bán cam của hộ bằng mô hình hồi quy với 9 biến độc lập, vậy số mẫu tối thiểu cần điều tra là 122 hộ. Thực tế nghiên cứu điều tra 150 hộ trồng cam để đảm bảo độ tin cậy cao hơn. Từ danh sách các hộ trồng cam do địa phương cung cấp, nghiên cứu chọn ngẫu nhiên 150 hộ đại diện cho các vùng sản xuất trong quy hoạch và ngoài quy hoạch, trong đó: huyện Hàm Yên 90 hộ; huyện Chiêm Hóa 30 hộ; huyện Yên Sơn 30 hộ.

\section{KẾT QUẢ NGHIÊN CÚU VÀ THẢO LUẬN}

3.1. Đánh giá kết quả và hiệu quả kinh tế sản xuất cam của hộ điều tra

Các chỉ tiêu đánh giá hiệu quả kinh tế sản xuất cam của hộ điều tra qua 3 năm được trình bày ở bảng 3 . Số liệu cho thấy năng suất cam bình quân tăng 4,4\% năm, tuy nhiên giá bán cam trong 3 năm qua liên tục giảm với tốc độ $9 \% / n a ̆ m$, dẫn đến doanh thu bán cam trên ha giảm $5 \% /$ năm. Trong khi các khoản mục chi phí sản xuất đều tăng, nhưng giá bán cam giảm mạnh dẫn đến các chỉ tiêu về giá trị gia tăng và thu nhập hỗn hợp đều giảm nhanh. Các chỉ tiêu phản ánh hiệu quả kinh tế sản xuất cam của hộ cũng giảm nhanh qua các năm với tốc độ giảm bình quân của các chỉ tiêu DT/TC là 7,6\%/năm, VA/TC giảm 10,7\%/năm, MI/TC giảm 14,6\%/năm.

Bảng 3. Hiệu quả kinh tế sản xuất cam của nông hộ giai đoạn 2017 - 2019

(tính cho 1 ha cam thò̀ kỳ kinh doanh)

\begin{tabular}{|c|c|c|c|c|c|c|c|c|}
\hline \multirow[b]{2}{*}{ TT } & \multirow[b]{2}{*}{ Chỉ tiêu } & \multirow[b]{2}{*}{ ĐVT } & \multicolumn{3}{|c|}{ Giá trị } & \multicolumn{3}{|c|}{ So sánh (\%) } \\
\hline & & & $\begin{array}{l}\text { Năm } \\
2017\end{array}$ & $\begin{array}{l}\text { Năm } \\
2018\end{array}$ & $\begin{array}{l}\text { Năm } \\
2019\end{array}$ & $\begin{array}{l}2018 / \\
2017\end{array}$ & $\begin{array}{l}2019 / \\
2018\end{array}$ & BQ \\
\hline 1 & Kết quả sản xuất & & & & & & & \\
\hline 1.1 & Năng suất bình quân & $\mathrm{kg} / \mathrm{ha}$ & 17.700 & 18.600 & 19.300 & 105,1 & 103,8 & 104,4 \\
\hline 1.2 & Giá bán bình quân & $\mathrm{d} / \mathrm{kg}$ & 9.302 & 7.950 & 7.700 & 85,5 & 96,9 & 91,0 \\
\hline
\end{tabular}




\begin{tabular}{|c|c|c|c|c|c|c|c|c|c|}
\hline \multirow[b]{2}{*}{ TT } & \multirow{2}{*}{\multicolumn{2}{|c|}{ Chỉ tiêu }} & \multirow[b]{2}{*}{ ĐVT } & \multicolumn{3}{|c|}{ Giá trị } & \multicolumn{3}{|c|}{ So sánh (\%) } \\
\hline & & & & $\begin{array}{l}\text { Năm } \\
2017\end{array}$ & $\begin{array}{l}\text { Năm } \\
2018\end{array}$ & $\begin{array}{l}\text { Năm } \\
2019\end{array}$ & $\begin{array}{l}2018 / \\
2017\end{array}$ & $\begin{array}{l}2019 / \\
2018\end{array}$ & BQ \\
\hline 1.3 & \multicolumn{2}{|c|}{ Doanh thu bán cam (DT) } & tr.d/ha & 164,6 & 147,9 & 148,8 & 89,8 & 100,5 & 95,0 \\
\hline 1.4 & \multicolumn{2}{|c|}{ Chi phí trung gian (IC) } & tr.d/ha & 47,8 & 49,6 & 50,3 & 103,7 & 101,4 & 102,5 \\
\hline 1.5 & \multicolumn{2}{|c|}{ Chi phí lao động(CL) } & tr.d/ha & 28,3 & 29,4 & 30,1 & 104,0 & 102,4 & 103,2 \\
\hline 1.6 & \multicolumn{2}{|c|}{ Tổng chi phí (TC) } & tr.d/ha & 76,1 & 79 & 80,4 & 103,8 & 101,8 & 102,8 \\
\hline 1.7 & \multicolumn{2}{|c|}{ Giá trị gia tăng (VA) } & tr.đ/ha & 116,8 & 98,3 & 98,3 & 84,1 & 100,0 & 91,7 \\
\hline 1.8 & Thu nhập & nỗn hợp (MI) & tr.d/ha & 88,5 & 68,9 & 68,4 & 77,8 & 99,0 & 87,8 \\
\hline 2 & \multicolumn{9}{|c|}{ Hiệu quả kinh tế } \\
\hline 2.1 & & DT/IC & lần & 3,4 & 3,0 & 3,0 & 86,6 & 99,1 & 92,7 \\
\hline 2.2 & & $\mathrm{VA} / \mathrm{IC}$ & lần & 2,4 & 2,0 & 2,0 & 81,2 & 98,6 & 89,5 \\
\hline 2.3 & & $\mathrm{MI} / \mathrm{IC}$ & lần & 1,9 & 1,4 & 1,4 & 75,0 & 97,7 & 85,6 \\
\hline 2.4 & & $\mathrm{DT} / \mathrm{TC}$ & lần & 2,2 & 1,9 & 1,8 & 86,5 & 98,8 & 92,4 \\
\hline 2.5 & & $\mathrm{VA} / \mathrm{TC}$ & lần & 1,5 & 1,2 & 1,2 & 81,0 & 98,3 & 89,3 \\
\hline 2.6 & & $\mathrm{MI} / \mathrm{TC}$ & lần & 1,2 & 0,9 & 0,8 & 74,9 & 97,3 & 85,4 \\
\hline \multicolumn{10}{|c|}{ 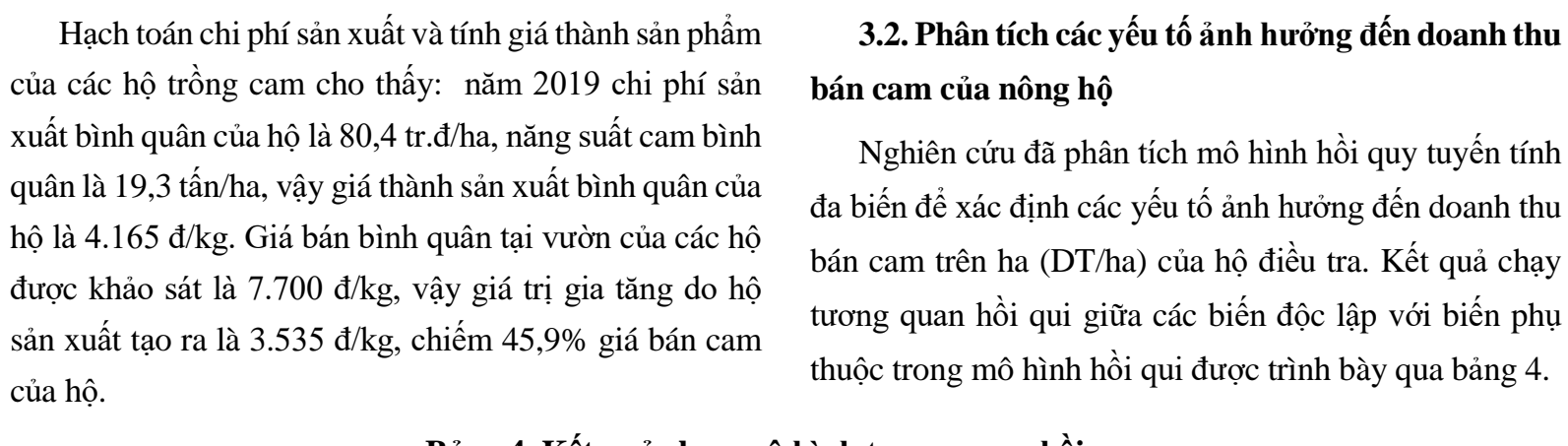 } \\
\hline \multicolumn{10}{|c|}{ Bảng 4. Kết quả chạy mô hình tương quan hồi quy } \\
\hline \multicolumn{2}{|c|}{ Biến độc lập } & $\begin{array}{cc}\text { Giá trị } & \mathbf{F} \\
\text { trung } & \\
\text { bình } & \end{array}$ & $\begin{array}{c}\text { Hệ số hồi quy } \\
\text { chưa chuẩn } \\
\text { hóa }(B)\end{array}$ & & $\begin{array}{l}\text { Mức ý nghĩa } \\
\text { thống kê } \\
\text { (Sig.) }\end{array}$ & VIF & $\begin{array}{l}\text { Hệs } \\
\text { quy } \\
\text { hóa }\end{array}$ & $\begin{array}{l}\text { ố hồi } \\
\text { huẩn } \quad t \\
\text { Beta) }\end{array}$ & $\begin{array}{l}\text { Giá trị } \\
\text { tuyệt đối } \\
\text { của Beta }\end{array}$ \\
\hline Hệ số & chặn & & 115,844 & $39,800^{* *}$ & 0,000 & & & & \\
\hline Kinh & nghiệm & 10,6 & 0,842 & $3,355^{* *}$ & 0,001 & 1,594 & & 144 & 0,144 \\
\hline Tập & nuấn & 3,7 & 4,917 & $5,706^{* *}$ & 0,000 & 4,679 & & 420 & 0,420 \\
\hline Quy & hoạch & 0,6 & 22,108 & $6,957^{* *}$ & 0,000 & 2,612 & &, 383 & 0,383 \\
\hline Vay & & 0,52 & 10,975 & $5,025^{* *}$ & 0,000 & 1,271 & & 193 & 0,193 \\
\hline Mô 1 & & 0,33 & 5,966 & $2,262^{*}$ & 0,025 & 1,553 & &, 096 & 0,096 \\
\hline Liên & & 0,47 & $-1,924$ & $-0,659^{\mathrm{NS}}$ & 0,511 & 2,290 & & 034 & 0,034 \\
\hline CPS & $\mathrm{X} / \mathrm{ha}$ & 80,4 & 1,185 & $6,624^{* *}$ & 0,000 & 3,957 & &, 333 & 0,333 \\
\hline Thu & hoạch & 0,52 & $-2,344$ & $-1,058^{\mathrm{NS}}$ & 0,292 & 1,321 & & 041 & 0,041 \\
\hline Tiêu & & 0,40 & 4,798 & $2,058^{*}$ & 0,041 & 1,360 & & 082 & 0,082 \\
\hline Biến & ố phụ thuộ & DT/ha (triệu c & đồng/năm): 148 & & & & & & \\
\hline Dung & lượng mẫu & uuan sát & 150 & & & & & & \\
\hline $\mathrm{F}$ & & & 90,3 & & & & & & \\
\hline
\end{tabular}




\begin{tabular}{|c|c|c|c|c|c|c|c|}
\hline Biến độc lập & $\begin{array}{c}\text { Giá trị } \\
\text { trung } \\
\text { bình }\end{array}$ & $\begin{array}{c}\text { Hệ số hồi quy } \\
\text { chưa chuẩn } \\
\text { hóa (B) }\end{array}$ & Giá trị t & $\begin{array}{c}\text { Mức ý nghĩa } \\
\text { thống kê } \\
\text { (Sig.) }\end{array}$ & VIF & $\begin{array}{l}\text { Hệ số hồi } \\
\text { quy chuẩn } \\
\text { hóa (Beta) }\end{array}$ & $\begin{array}{l}\text { Giá trị } \\
\text { tuyệt đối } \\
\text { của Beta }\end{array}$ \\
\hline Hệ số $\mathrm{R}^{2}$ & & 0,8 & & & & & \\
\hline Hệ số $\mathrm{R}^{2}$ hiệu chỉnh & & 0,8 & & & & & \\
\hline Durbin-Watson & & 1,0 & & & & & \\
\hline
\end{tabular}

Ghi chú: ** Mức ý nghĩa <0,01; * Mức ý nghĩa <0,05; NS: Không có ý nghĩa thống kê

Số liệu cho thấy hệ số $\mathrm{R}^{2}$ hiệu chỉnh đạt giá trị 0,827 , điều này có nghĩa là $82,7 \%$ sự thay đổi về DT/ha của hộ trồng cam được giải thích bởi các biến độc lập trong mô hình, như vậy có thể kết luận mô hình đưa ra là phù hợp với thực tế. Hệ số phóng đại phương sai (VIF) đều nhỏ hơn 10, như vậy mô hình hồi qui không có hiện tượng đa cộng tuyến. Hệ số Durbin-Watson $(1<\mathrm{d}=1,096<3)$, nghĩa là mô hình hồi qui không có hiện tượng tự tương quan. Kết quả từ hình 1 cho thấy mô hình hồi qui không có hiện tượng phương sai của sai số thay đổi vì phân bố của phần dư thuộc phân phối chuẩn.

\section{Hình 1. Kết quả kiểm định hiện tượng phương sai của sai số thay đổi}

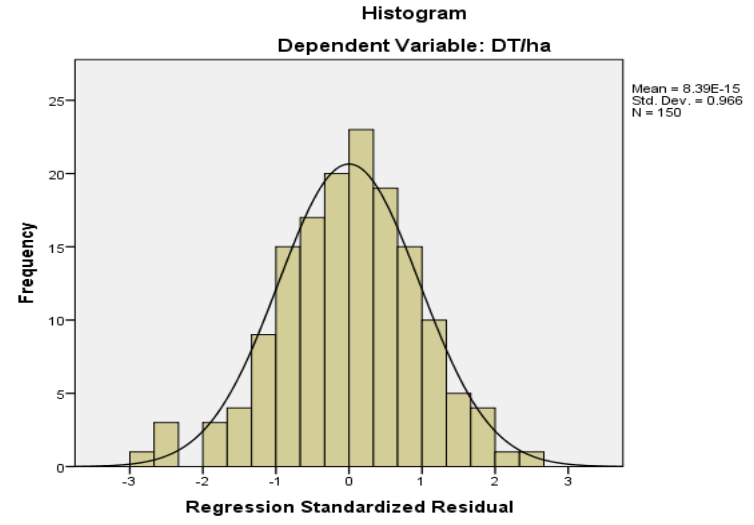

Kết quả bảng 4 cho thấy mức ý nghĩa thống kê (cột sig.) của các biến Kinh nghiệm; Tập huấn; Quy hoạch; Vay vốn; Mô hình; CPSX/ha; Tiêu thụ có mức ý nghĩa thống kê $\mathrm{P}<0,05$, các nhân tố này có ảnh hưởng đến doanh thu bán cam hàng hóa của hộ trồng cam trên địa bàn nghiên cứu với độ tin cậy 95\%. Kết quả kiểm định cũng cho thấy các nhân tố trên có ý nghĩa thống kê và đều có quan hệ cùng chiều với biến phụ thuộc DT/ha và đúng như kỳ vọng dấu đặt ra ban đầu. Điều đó có nghĩa là khi gia tăng các biến trên sẽ có tác động tích cực làm gia tăng doanh thu bán cam hàng hóa bình quân trên 1 ha diện tích trồng cam của hộ. Cụ thể: Khi tăng 1 năm kinh nghiệm trồng cam của chủ hộ sẽ làm DT/ha tăng 0,144 triệu đồng. Khi tăng số lần tập huấn cho hộ trồng cam thêm 1 lần/năm thì sẽ làm gia tăng DT/ha của hộ lên 0,42 triệu đồng. Hộ sản xuất cam được nằm trong vùng quy hoạch sẽ làm giá trị DT/ha tăng lên 0,383 triệu đồng. Hộ vay vốn để đầu tư cho sản xuất cam sẽ làm giá trị DT/ha tăng lên 0,193 triệu đồng. Hộ tham gia sản xuất cam theo

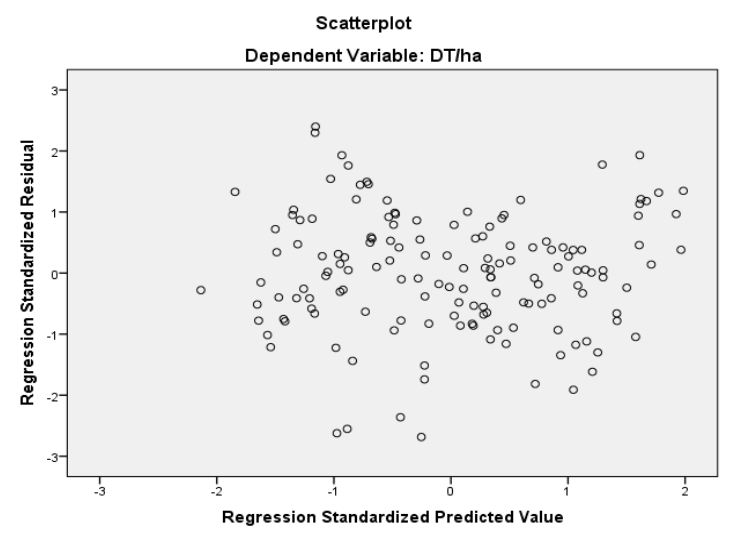

(Nguồn: Kết quả khảo sát 2019)

mô hình VietGAP sẽ làm giá trị DT/ha tăng lên 0,096 triệu đồng. Khi tăng 1 triệu đồng chi phí sản xuất/ha sẽ làm gia tăng DT/ha của hộ lên 0,333 triệu đồng. Hộ tiêu thụ cam kết hợp cả phương thức bán buôn và bán lẻ sẽ làm giá trị DT/ha tăng lên 0,082 triệu đồng. Kết quả của mô hình hồi quy tuyến tính đa biến về các nhân tố ảnh hưởng đến doanh thu bán cam bình quân trên ha (DT/ha) của hộ điều tra là cơ sở để đề xuất một số giải pháp phát triển sản xuất cam theo hướng hàng hóa trên địa bàn nghiên cứu.

\subsection{Phân tích các yếu tố ảnh hưởng đến hiệu quả kinh tế sản xuất cam của nông hộ}

\subsubsection{Các yếu tố thuộc về nguồn lục sản xuất}

* Điều kiện sản xuất của hộ trồng cam

Các điều kiện sản xuất của hộ trồng cam như độ tuổi, trình độ văn hóa, số năm kinh nghiệm trồng cam, số khẩu, số lao động, diện tích trồng cam... có ảnh hưởng lớn đến hiệu quả sản xuất cam của hộ. Vì vậy, để đánh giá hiệu 
quả kinh tế, nghiên cứu tổng hợp các đặc điểm cơ bản của hộ trồng cam qua bảng 5 . Số liệu cho thấy tuổi bình quân của chủ hộ trồng cam là 48 tuổi, đây là độ tuổi chín muồi, hội tụ các yếu tố về kinh nghiệm, trí lực và sự gắn bó lâu dài của chủ hộ đối với quá trình phát triển sản xuất cam, tuy nhiên đây cũng là độ tuổi già so với tuổi lao động bình quân, sẽ là yếu tố hạn chế sự năng động, nhạy bén trong phát triển kinh tế hàng hóa, thị trường, sự hạn chế về thể lực trong lao động sản xuất. Trình độ văn hóa bình quân của chủ hộ tương đối thấp $(7,2 / 12)$, đây là yếu tố hạn chế khả năng tiếp thu, ứng dụng những tiến bộ khoa học kỹ thuật tiên tiến vào sản xuất kinh doanh. Tuy nhiên, số năm kinh nghiệm trồng cam bình quân của chủ hộ khá cao, đạt 10,6 năm là lợi thế lớn trong phát huy những kiến thức tích lũy lâu dài, những kinh nghiệm, kỹ thuật trong sản xuất cam phù hợp với các điều kiện cụ thể của địa phương.

Bảng 5. Đặc điểm cơ bản của các hộ điều tra

\begin{tabular}{rllrrr}
\hline TT & \multicolumn{1}{c}{ Chỉ tiêu } & ĐVT & \multicolumn{1}{c}{$\begin{array}{c}\text { Vùng } \\
\text { QH }\end{array}$} & $\begin{array}{c}\text { Vùng } \\
\text { ngoài } \mathbf{Q H}\end{array}$ & Tính chung \\
\hline 1 & Số hộ điều tra & hộ & 90 & 60 & 150 \\
2 & Tuổi của chủ hộ & tuổi & 47,3 & 49,6 & 48,0 \\
3 & Trình độ văn hóa & lớp & 8,9 & 4,7 & 7,2 \\
4 & Số năm kinh nghiệm trồng cam & năm & 11,3 & 9,7 & 10,6 \\
5 & Số khẩu & người & 4,6 & 4,4 & 4,5 \\
6 & Số lao động & người & 2,71 & 2,68 & 2,7 \\
7 & Diện tích đất trồng cam & ha & 1,6 & 1,4 & 1,51 \\
8 & Tỉ lệ hộ vay vốn cho sản xuất cam & $\%$ & 53 & 49 & 52 \\
9 & Thu nhập từ trồng cam/Tổng TN & $\%$ & 83 & 55 & 72 \\
\hline
\end{tabular}

Số khẩu bình quân của hộ lớn, trong khi số lao động bình quân thấp, điều này cũng thể hiện đặc điểm gia đình sống nhiều thế hệ của người dân địa phương. Lao động gia đình ít cũng tạo ra nhu cầu lớn về lao động thuê ngoài, đặc biệt những lúc sản xuất mang tính thời vụ cao. Thu nhập chủ yếu của các hộ điều tra là từ sản xuất và tiêu thụ cam, chiếm $72 \%$ trong tổng số thu nhập hàng năm của hộ, điều này cho thấy xu hướng tập trung, chuyên môn hóa trong sản xuất cam của nông hộ.

\section{* Quy mô sản xuát}

Diện tích vườn cam, mức độ đầu tư chi phí, số lao động của hộ tham gia trực tiếp sản xuất là các chỉ tiêu đánh giá quy mô, năng lực sản xuất hàng hóa của hộ trồng cam. Số liệu ở bảng 6 tổng hợp nhằm phân tích ảnh hưởng của quy mô sản xuất đến hiệu quả kinh tế sản xuất cam của các nhóm hộ.

Bảng 6. Ảnh hưởng của quy mô sản xuất đến hiệu quả kinh tế sản xuất cam của hộ

\begin{tabular}{|c|c|c|c|c|c|c|c|c|}
\hline TT & Chỉ tiêu & $\begin{array}{c}\text { Số hộ } \\
\text { (hộ) }\end{array}$ & $\begin{array}{l}\text { Tỉ lệ } \\
(\%)\end{array}$ & $\begin{array}{c}\text { Năng } \\
\text { suất } \\
\text { (tấn/ha) }\end{array}$ & $\begin{array}{c}\text { Sản } \\
\text { lưọng } \\
\text { (tấn/ hộ) }\end{array}$ & $\begin{array}{c}\text { DT } \\
\text { (tr.đ/hộ) }\end{array}$ & $\begin{array}{c}\text { IC } \\
\text { (tr.đ/hộ) }\end{array}$ & $\begin{array}{c}\text { MI } \\
\text { (tr.d/hộ) }\end{array}$ \\
\hline 1 & Diện tích vưò̀n cam & & & & & & & \\
\hline 1.1 & Quy mô nhỏ (dưới 1 ha) & 58 & 38,7 & 18,4 & 12 & 92,1 & 50 & 42,2 \\
\hline 1.2 & Quy mô TB (từ 1 - 2 ha) & 58 & 38,7 & 19,4 & 31 & 235,9 & 124,4 & 111,5 \\
\hline 1.3 & Quy mô lớn (trên 2 ha) & 34 & 22,7 & 20,5 & 54 & 445,8 & 244 & 201,7 \\
\hline 2 & Chi phí đầu tư & & & & & & & \\
\hline 2.1 & Dưới 100 triệu/ năm & 62 & 41,3 & 18,4 & 13,1 & 100,1 & 53,7 & 46,3 \\
\hline 2.2 & Từ 100 - 200 triệu/ năm & 61 & 40,7 & 18,9 & 32,6 & 250,8 & 137,6 & 113,1 \\
\hline
\end{tabular}




\begin{tabular}{clrrrrrrr}
\hline TT & \multicolumn{1}{c}{ Chỉ tiêu } & $\begin{array}{c}\text { Số hộ } \\
\text { (hộ) }\end{array}$ & $\begin{array}{c}\text { Tỉ lệ } \\
(\boldsymbol{\%})\end{array}$ & $\begin{array}{c}\text { Năng } \\
\text { suất } \\
\text { (tấn/ha) }\end{array}$ & $\begin{array}{c}\text { Sản } \\
\text { lượng } \\
\text { (tấn/hộ) }\end{array}$ & $\begin{array}{c}\text { DT } \\
\text { (tr.d/hộ) }\end{array}$ & $\begin{array}{c}\text { IC } \\
\text { (tr.d/hộ) }\end{array}$ & $\begin{array}{c}\text { MI } \\
\text { (tr.d/hộ) }\end{array}$ \\
\hline 2.3 & Trên 200 triệu/năm & 27 & 18,0 & 22,0 & 63,7 & 497,3 & 264,3 & 233 \\
$\mathbf{3}$ & Lao động của hộ & & & & & & & \\
3.1 & Dưới 3 người & 79 & 52,7 & 18,1 & 18,9 & 144,1 & 81,8 & 62,3 \\
3.2 & Từ 3 người trở lên & 71 & 47,3 & 20,6 & 42,6 & 331,6 & 174,6 & 157 \\
\hline & Tính chung & $\mathbf{1 5 0}$ & $\mathbf{1 0 0 , 0}$ & $\mathbf{1 9 , 3}$ & $\mathbf{3 0 , 1}$ & $\mathbf{2 3 2 , 8}$ & $\mathbf{1 2 5 , 7}$ & $\mathbf{1 0 7 , 1}$ \\
\hline
\end{tabular}

Số liệu cho thấy nhóm hộ có quy mô sản xuất cam càng cao thì mang lại hiệu quả kinh tế càng cao. Về diện tích vườn cam, nhóm hộ có quy mô lớn (trên 2 ha) chiếm 22,7\% tổng số hộ khảo sát, nhóm này có mức đầu tư cao nhất, nhưng cũng đạt các giá trị cao nhất về năng suất, sản lượng, giá trị sản xuất và thu nhập hỗn hợp so với các nhóm hộ quy mô trung bình và quy mô nhỏ. Xét về mức chi phí đầu tư bình quân của các nhóm hộ cũng cho thấy nhóm hộ có mức đầu tư trên 200 triệu đồng/năm là nhóm hộ có mức đầu tư cao nhất, và cũng đạt hiệu quả kinh tế cao nhất trong sản xuất cam. Về lao động của hộ, nhóm hộ có số lao động trên 3 người/hộ chiếm 47,3\%, đây là những lao động trực tiếp của hộ, tham gia tất cả các khâu trong quá trình trồng mới, chăm sóc và thu hoạch cam. Số liệu cho thấy nhóm hộ có số lao động của hộ tham gia sản xuất cam càng lớn thì mang lại hiệu quả kinh tế sản xuất cam càng cao.

\section{* Nguồn vốn đầu tu}

Trong số 150 hộ trồng cam được khảo sát có 78 hộ có vay vốn ngân hàng hoặc các tổ chức tín dụng, chiếm $52 \%$. Đa số các hộ vay vốn với mục đích cải tạo và trồng mới vườn cam, sản xuất cam theo mô hình VietGAP, đầu tư trang bị máy móc, mua vật tư phân bón và ứng dụng khoa học kỹ thuật cho sản xuất sản phẩm, vậy nên việc sử dụng vốn vay đã mang lại hiệu quả kinh tế trong sản xuất cam của hộ.

Bảng 7. Ảnh hưởng của vay vốn đến hiệu quả sản xuất cam của hộ

\begin{tabular}{lrrrrr}
\hline \multicolumn{1}{c}{ Chỉ tiêu } & Số hộ & \multicolumn{1}{c}{ Tỉ lệ } & \multicolumn{1}{c}{$\begin{array}{c}\text { Chi phí sản xuất } \\
\text { (đồng /ha) }\end{array}$} & \multicolumn{1}{c}{$\begin{array}{c}\text { Doanh thu } \\
\text { (đồng /ha) }\end{array}$} & $\begin{array}{c}\text { Thu nhập hỗn họ̣p } \\
\text { (đồng /ha) }\end{array}$ \\
\hline Hộ vay vốn (1) & 78 & $87 \%$ & 81.589 .355 & 158.013 .457 & 76.424 .102 \\
Hộ không vay vốn (2) & 72 & $80 \%$ & 79.111 .532 & 138.803 .823 & 59.692 .291 \\
Chênh lệch (1) - (2) & 6 & $7 \%$ & 2.477 .823 & 19.209 .634 & 16.731 .811 \\
\hline \multicolumn{1}{c}{ Tính chung } & $\mathbf{1 5 0}$ & $\mathbf{1 0 0 \%}$ & $\mathbf{8 0 . 4 0 0 . 0 0 0}$ & $\mathbf{1 4 8 . 7 9 2 . 8 3 3}$ & $\mathbf{6 8 . 3 9 2 . 8 3 3}$ \\
\hline
\end{tabular}

Số liệu ở bảng 7 cho thấy so với các hộ không vay vốn thì các hộ sử dụng vốn vay có chi phí sản xuất cao hơn, nhưng doanh thu bán cam và thu nhập của hộ lại đạt được ở mức cao hơn nên có hiệu quả kinh tế hơn.

\subsubsection{Các yếu tố thuộc về tổ chức sản xuất}

* Mô hình sản xuất cam theo tiêu chuẩn VietGAP

Có 33\% hộ điều tra có tham gia sản xuất cam theo mô hình VietGAP. Đa số các hộ thuộc nhóm này là hộ sản xuất cam điển hình tiến tiến, có quy mô sản xuất lớn, thường xuyên tham gia các lớp tập huấn, áp dụng các tiến bộ khoa học kỹ thuật vào sản xuất, tham gia liên kết trong sản xuất và tiêu thụ sản phẩm. So với nhóm hộ sản xuất cam theo mô hình truyền thống thì nhóm hộ sản xuất cam theo mô hình VietGAP đạt được hiệu quả kinh tế cao hơn.

Bảng 8. Ảnh hưởng của mô hình sản xuất đến hiệu quả sản xuất cam của hộ

\begin{tabular}{llcccc}
\hline Chỉ tiêu & ĐVT & $\begin{array}{c}\text { Mô hình SX } \\
\text { truyền } \\
\text { thống }(0)\end{array}$ & $\begin{array}{c}\text { Mô hình SX } \\
\text { VietGAP }(1)\end{array}$ & $\begin{array}{c}\text { Chênh lệch } \\
\text { (1) và (0) }\end{array}$ & $\begin{array}{c}\text { Tính } \\
\text { chung }\end{array}$ \\
\hline
\end{tabular}




\begin{tabular}{llrrrr}
\hline Số hộ & hộ & 100 & 50 & $(50)$ & 150 \\
Tỉ lệ & $\%$ & 66,7 & 33,3 & $(33,4)$ & 100 \\
Chi phí sản xuất & tr.đ/ha & 78,1 & 84,8 & 6,7 & 80,4 \\
Năng suất & tấn/ha & 18 & 21,9 & 3,8 & 19,3 \\
Giá bán bình quân & ng.đ/kg & 7.679 & 7.741 & 62 & 7.700 \\
Giá trị sản xuất hàng hóa/ha & tr.đ/ha & 138,4 & 169,5 & 31,1 & 148,8 \\
Thu nhập hỗn hợp/ha & tr.đ/ha & 60,2 & 84,7 & 24,4 & 68,4 \\
Giá trị cam hàng hóa/hộ & tr.đ/hộ & 227,6 & 243,3 & 15,6 & 232,8 \\
Thu nhập hỗn hợp/hộ & tr.đ/hộ & 98,5 & 124,2 & 25,6 & 107,1 \\
\hline
\end{tabular}

Với nhóm hộ sản xuất cam theo mô hình VietGAP có chi phí đầu tư sản xuất cao hơn so với nhóm hộ sản xuất truyền thống là 6,7 triệu đồng/ha, do mức đầu tư cho giống, vật tư, công chăm sóc cao hơn. Tuy nhiên năng suất cam của nhóm hộ này cũng cao hơn 3,8 tấn/ha, cùng với các yếu tố có lợi khác từ sản xuất cam theo mô hình VietGAP mang lại như chất lượng sản phẩm tốt, liên kết trong tiêu thụ sản phẩm, xây dựng thương hiệu sản phẩm nên nhóm hộ này có giá bán sản phẩm cao hơn bình quân là 62 đ $/ \mathrm{kg}$. Kết hợp với các yếu tố về quy mô diện tích, sản lượng hàng hóa cao hơn làm cho các chỉ tiêu đánh giá kết quả và hiệu quả kinh tế sản xuất cam của nhóm hộ sản xuất theo mô hình VietGAP đều cao hơn so với nhóm hộ sản xuất theo mô hình truyền thống và mức bình quân chung của vùng nghiên cứu. Đây là căn cứ để đề xuất giải pháp tăng cường nhân rộng mô hình sản xuất cam VietGAP trong phát triển sản xuất cam ở Tỉnh.
* Tổ chức vùng sản xuất cam theo hướng hàng hóa

Khảo sát thực tế cho thấy tổ chức vùng sản xuất có ảnh hưởng đến hiệu quả kinh tế sản xuất cam của các hộ điều tra. Các hộ sản xuất cam nằm trong vùng quy hoạch được hưởng các chính sách ưu đãi về cho vay vốn, chính sách hỗ trợ về giống, khoa học kỹ thuật, liên kết trong sản xuất và tiêu thụ sản phẩm, chính sách tích tụ, tập trung ruộng đất, chính sách phát triển cơ sở hạ tầng vùng quy hoạch, chính sách đào tạo, tập huấn cho các hộ trồng cam. Đánh giá tác động của các chính sách này đến hiệu quả sản xuất cam hàng hóa của các hộ, nghiên cứu đã tổng hợp các chỉ tiêu kinh tế theo hai nhóm hộ: nhóm hộ thuộc vùng quy hoạch và nhóm hộ nằm ngoài vùng quy hoạch sản xuất cam của Tỉnh. Kết quả tính toán được tổng hợp qua bảng 9 .

Bảng 9. Ảnh hưởng của tổ chức vùng sản xuất đến hiệu quả kinh tế sản xuất cam

\begin{tabular}{|c|c|c|c|c|c|}
\hline TT & Chỉ tiêu & ĐVT & $\begin{array}{l}\text { Hộ ngoài } \\
\text { vùng quy } \\
\text { hoạch } \\
\text { (NQH) }\end{array}$ & $\begin{array}{c}\text { Hộ trong } \\
\text { vùng quy } \\
\text { hoạch }(\mathrm{QH})\end{array}$ & $\begin{array}{c}\text { So sánh } \\
\text { QH/NQH } \\
\text { (lần) }\end{array}$ \\
\hline 1 & Số hộ khảo sát & hộ & 60 & 90 & 1,5 \\
\hline 2 & Diện tích trồng cam & ha & 1,41 & 1,58 & 1,1 \\
\hline 3 & Số lần tham gia tập huấn/năm & lần & 1,5 & 5,2 & 3,4 \\
\hline 4 & Tỉ lệ hộ vay vốn & $\%$ & 50 & 53 & 1,1 \\
\hline 5 & Tỉ lệ hộ sản xuất theo mô hình VietGAP & $\%$ & 0 & 56 & - \\
\hline 6 & Tỉ lệ hộ tham gia liên kết & $\%$ & 28 & 59 & 2,1 \\
\hline 7 & Năng suất & tấn/ha & 16,4 & 21,2 & 1,3 \\
\hline 8 & Sản lượng & tấn/hộ & 23,3 & 34,6 & 1,3 \\
\hline 9 & Giá bán bình quân & $\mathrm{d} / \mathrm{kg}$ & 7.650 & 7.750 & 1,0 \\
\hline
\end{tabular}




\begin{tabular}{llrrrr}
10 & Giá trị sản phẩm hàng hóa & tr.đ & 179,3 & 268,5 & 1,5 \\
11 & Chi phí sản xuất & tr.đ & 105,5 & 139,2 & 1,3 \\
12 & Thu nhập hỗn hợp & tr.đ & 73,7 & 129,3 & 1,8 \\
\hline
\end{tabular}

Số liệu bảng 9 cho thấy: Diện tích trồng cam bình quân của nhóm hộ thuộc vùng quy hoạch cao hơn so với nhóm hộ ngoài vùng quy hoạch, điều này cũng cho thấy hiệu quả của chính sách tích tụ, tập trung ruộng đất cho phát triển sản xuất cam hàng hóa. Số lần tham gia tập huấn, tỉ lệ hộ vay vốn, tỉ lệ hộ sản xuất cam theo mô hình VietGAP, tỉ lệ hộ tham gia liên kêt trong sản xuất và tiêu thụ cam thuộc vùng quy hoạch đều cao hơn so với nhóm hộ trồng cam ngoài vùng quy hoạch. Hiệu suất quy mô làm cho năng suất, giá bán và sản lượng cam của nhóm hộ thuộc vùng quy hoạch đều cao hơn, đồng thời các chỉ tiêu phản ánh hiệu quả kinh tế sản xuất cam hàng hóa cũng cao hơn nhóm hộ ngoài vùng quy hoạch. Để nâng cao hiệu quả kinh tế sản xuất cam cho nông hộ, chính quyền địa phương cần rà soát, điều chỉnh và bổ sung vùng quy hoạch sản xuất cam tập trung và có các chính sách hỗ trợ đồng bộ cho các hộ trồng cam.

\section{* Thời điểm tiêu thu cam}

Cam ở Tuyên Quang cho thu hoạch một vụ/năm, thời gian thu hoạch kéo dài từ đầu tháng 9 đến cuối tháng 3 năm sau. Sản phẩm thu hoạch từ lúc cam còn xanh và bắt đầu mọng nước đến khi cam chín vàng và chín héo trên cây. Tùy thuộc vào tình hình thu mua và giá bán mà hộ trồng cam ra quyết định bán cam chính vụ hoặc sớm hay muộn. Thu hoạch chính vụ diễn ra tập trung trong các tháng $11,12,01$ của niên vụ.

Bảng 10. Ảnh hưởng của thời điểm tiêu thụ đến hiệu quả kinh tế sản xuất cam

\begin{tabular}{|c|c|c|c|c|c|}
\hline Chỉ tiêu & Số hộ & $\begin{array}{l}\text { Tỉ lệ } \\
(\%)\end{array}$ & $\begin{array}{l}\text { Giá bán } \\
\text { (đồng /kg) }\end{array}$ & $\begin{array}{c}\text { Giá trị hàng } \\
\text { hóa (đồng /ha) }\end{array}$ & $\begin{array}{l}\text { Thu nhập hỗn } \\
\text { hợp (đồng /ha) }\end{array}$ \\
\hline Hộ thu hoạch chính vụ (0) & 72 & 48 & 7.581 & 145.485 .914 & 64.919 .158 \\
\hline Hộ thu hoạch trái vụ hoặc kết hợp (1) & 78 & 52 & 7.810 & 151.845 .373 & 71.599 .302 \\
\hline Chênh lệch (1) - (0) & 6 & 4 & 229 & 6.359 .459 & 6.680 .143 \\
\hline Tính chung & 150 & 100 & 7.700 & 148.792 .833 & 68.392 .833 \\
\hline
\end{tabular}

Số liệu bảng 10 cho thấy có $48 \%$ hộ thu hoạch chính vụ và chủ yếu tiêu thụ theo phương thức bán buôn cho các thương lái đường dài. Phương thức này chủ yếu phù hợp với các hộ sản xuất quy mô lớn, sản lượng cam hàng hóa nhiều. Có 52\% hộ thu hoạch cam trái vụ hoặc kết hợp, thời điểm thu hoạch linh hoạt theo tình hình giá cả và nhu cầu của thị trường, có thể thu hoạch sớm, thu hoạch đúng vụ hoặc thu hoạch muộn để chờ tăng giá. Số liệu khảo sát cũng cho thấy nhóm hộ này có giá bán trung bình là $7.810 \mathrm{~d} / \mathrm{kg}$, cao hơn so với nhóm hộ thu hoạch đúng vụ trung bình là $229 \mathrm{~d} / \mathrm{kg}$. Với quy mô sản xuất nhỏ thì hộ có thể linh hoạt quyết định thời điểm thu hoạch và phương thức tiêu thụ để có được giá bán tốt hơn. Khi tính hiệu quả sản xuất cam hàng hóa bình quân trên ha thì các chỉ tiêu giá bán, giá trị sản phẩm hàng hóa và thu nhập hỗn hợp của nhóm hộ thu hoạch trái vụ hoặc kết hợp cao hơn so với nhóm hộ thu hoạch chính vụ. Các phân tích trên cho thấy, để tăng hiệu quả kinh tế trong sản xuất cam của hộ cần có giải pháp ổn định giá cả, thị trường, kéo dài thời gian tiêu thụ bằng biện pháp canh tác rải vụ hay áp dụng công nghệ bảo quản, chế biến, tăng cường liên kết trong sản xuất và tiêu thụ cam.

\section{KÊT LUẬN}

Sản xuất cam của nông hộ ở tỉnh Tuyên Quang trong những năm qua đã không ngừng gia tăng diện tích, năng suất và sản lượng cam hàng hóa. Tuy nhiên, việc tiêu thụ cam còn khó khăn, giá bán không ổn định dẫn đến các chỉ tiêu hạch toán hiệu quả kinh tế sản xuất cam của nông hộ liên tục giảm trong 3 năm qua. Phân tích các yếu tố ảnh hưởng đến doanh thu bán cam của hộ cho thấy một số yếu tố có ảnh hưởng tích cực, nếu gia tăng các yếu tố này sẽ làm tăng doanh thu bán cam hàng hóa của hộ trồng cam như: kinh nghiệm sản xuất của chủ hộ, số lần tập huấn, chính sách quy hoạch, vốn vay, mô hình sản xuất cam VietGAP, mức độ đầu tư và phương thức tiêu thụ 
sản phẩm. Để nâng cao hiệu quả kinh tế sản xuất cam của nông hộ, cần thực hiện đồng bộ các giải pháp sau: nâng cao trình độ văn hóa và tăng cường tập huấn cho chủ hộ; có chính sách đẩy mạnh tích tụ ruộng đất, mở rộng quy mô diện tích vườn cam của hộ; khuyến khích và tạo điều kiện cho các hộ trồng cam vay vốn, tăng cường mức đầu từ cho sản xuất cam; nhân rộng mô hình sản xuất cam VietGAP; phát triển vùng quy hoạch sản xuất cam tập trung và có các chính sách hỗ trợ đồng bộ cho các hộ trồng cam; có giải pháp ổn định giá cả, thị trường, kéo dài thời gian tiêu thụ bằng biện pháp canh tác rải vụ hay áp dụng công nghệ bảo quản, chế biến, tăng cường liên kết trong sản xuất và tiêu thụ cam.

\section{TÀI LIỆU THAM KHẢO}

1. Cục Thống kê tỉnh Tuyên Quang (2019). Niên giám thống kê tỉnh Tuyên Quang 2018. Nhà xuất bản Thống kê, Hà Nội.
2. Sở Nông nghiệp và Phát triển Nông thôn tỉnh Tuyên Quang (2019). Báo cáo tình hình phát triển cây ăn quả có múi tỉnh Tuyên Quang.

3. Tabachnick, B. G., and Fidell, L. S. (1996). Using Multivariate Statistics (3rd ed.). New York: Harper Collins.

4. Trần Thị Diên (2019). Giải pháp phát triển sản xuất cam theo huớng hàng hóa ở tỉnh Tuyên Quang. Sách chuyên khảo. Nhà xuất bản Đại học Thái Nguyên. ISBN: 978-604-915-896-4.

5. Ủy ban nhân dân tỉnh Tuyên Quang (2014), Đề án Phát triển vùng sản xuất cam sành tỉnh Tuyên Quang, giai đoạn 2014-2020, Quyết định số 338/QĐ-UBND ngày 27/8/2014.

6. Ủy ban nhân dân tỉnh Tuyên Quang (2018). Quy hoạch sử dụng đất trồng cam huyện Hàm Yên và huyện Chiêm Hóa đến năm 2020, định huoóng đến năm 2030.

\section{Analyzing the factors affecting the results and economic efficiency of orange growers in Tuyen Quang province}

Tran Thi Dien

\section{Article info}

Recieved:

2/4/2020

Accepted:

$10 / 6 / 2020$

Keywords:

Oranges, economic efficiency, orange growers, Tuyen Quang, affecting factors, farmer' revenue and income.

\begin{abstract}
The study surveyed 150 orange growers in Tuyen Quang province and used economic research methods to analyze the factors affecting farmer' revenue and income from orange production. The analysis results from the multivariate regression model show that factors such as experience, training, planning, loans, VietGAP orange production model, level of investment, which have a positive impact on revenue of orange growers. The results of analyzing the factors affecting the economic efficiency are the basis for proposing solutions to increase the income of households, such as, Enhancing production capacity for farmers; Expanding the area of oranges/household; Increasing investment capital; Expanding VietGAP orange production model; Well-organized planning of concentrated production areas; Applying orange varieties for long-term harvest; applying preservation and processing to extend the time of product marketing; And strengthening linkages in oranges production and consumption.
\end{abstract}

